\title{
SUPERCONDUCTING MAGNETIC SEPARATORS
}

\author{
JUERGEN KOPP \\ Physics Department, University of the Witwatersrand, \\ Johannesburg, South Africa \\ (formerly at Oxford Instruments, Eynsham, England)
}

(Received February 13, 1991)

Abstract The fields available with conventional electromagnets are limited to 2 Tesla by the saturation of iron. In addition, the creation of large field volumes is costly in terms of copper, iron and electric power. For these reasons superconducting separator magnets were proposed as early as 1970. This paper deals with the special requirements of cryomagnets in the mineral processing industry, and the relatively slow rate of replacement of conventional magnets. Finally, the impact of the new high-temperature superconductors is examined briefly.

\section{INTRODUCTION}

In magnetic separation use is made of the enormous differences in the magnetic susceptibility of minerals (Fig. 1). A small weakly magnetic particle of mass m and mass susceptibility will experience a magnetic force [2]

$$
\mathrm{F}=\mathrm{m}\left(\chi / \mu_{\mathrm{o}}\right) \mathrm{B} \cdot \nabla \mathrm{B}
$$

where $B$ is the field and $\nabla$ B the field gradient. There are two ways of producing a gradient:

i. Open-gradient magnetic separators (OGMS) use the actual windings or poles to create weak gradients and forces that deflect magnetic particles.

ii. High-gradient magnetic separators (HGMS) use a finely divided ferromagnetic matrix to create large enough gradients and forces to capture magnetic particles.

The design of superconducting open-gradient magnets is difficult, since magnetic flux must be both large and rapidly varying, external to the cold region. Opposed current windings are generally used, as in cusp-mode split pair coils or "racetrack" linear dipoles [3]. In all cases the gradient is 
in the form B/c, where B is the field and $c$ a typical winding dimension. If $B=3 \mathrm{~T}$ and $c=0.1 \mathrm{~m}$ then $\nabla \mathrm{B}=30 \mathrm{~T} / \mathrm{m}$ and $B . \nabla B=90 \mathrm{~T}^{2} / \mathrm{m}$. Note that the magnetic force increases as the square of the field.

Matrix separators [4] generally make use of the quasihomogeneous field of solenoids, which are the easiest magnets to build. For fields at which the matrix is saturated the gradient will be $B=/$ a where Bs is the saturation field and $a$ is a typical matrix dimension. For $B=3 T, \quad B=2 T$ and $a=1 \mathrm{~mm}, \quad \nabla B=2000 \mathrm{~T} / \mathrm{m}$ and $\mathrm{B}, \quad \nabla \mathrm{B}=6000 \mathrm{~T} / \mathrm{m}$. Here the force only increases linearly with the field.

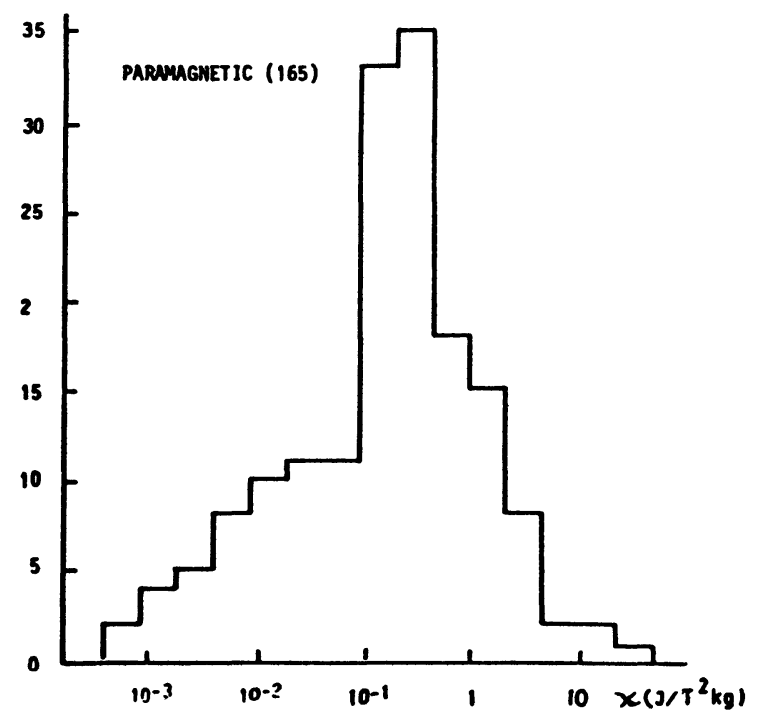

FIGURE 1. Distribution of the magnetic susceptibility of paramagnetic minerals (from [1]).

Table 1 shows some existing magnetic separators and Figure 2 indicates the regions of applicability in a susceptibilityparticle size continuum. Wet methods are invariably used for particle sizes below $75 \mu \mathrm{m}[5]$.

\section{MAGNETS FOR OPEN-GRADIENT SEPARATION}

We shall illustrate the requirements by a simple straight conductor of circular cross-section carrying a current $I$. The field at an external point $r$ is $\mu_{0} I / 2 \pi r$ and the field gradient is $B / r$. The force constant is thus

$$
f=B \cdot \nabla B=B^{2} / r=\left(\mu_{0} I / 2 \pi r\right)^{2} / r^{2}
$$


TABLE I Magnetic force factors of existing separators

Name

Low-intensity drums

Permrolls

S/c drum OGMS

S/c falling curtain

Induced magnetic roll Cu\&Fe

Jones separator

Carousel HGMS

Magnetic filters

NbTi

NbTi

Cu\&Fe
Magnet

Matrix

B. $\nabla$ B $\left(T^{2} / m\right)$
Ferrite

$\mathrm{Nd}-\mathrm{Fe}-\mathrm{B}$

Cu\&Fe

grooved plates

various

Cu\&fe fine wires or NbTi
1000

1

100

30

100

100

500

10000

For $I=1$ MA and $r=0.1 \mathrm{~m}$ the field will be $2 \mathrm{~T}$ and the force factor $40 \mathrm{~T}^{2} / \mathrm{m}$. A high force factor arises from:

i. high current density in the conductor

ii. small thermal insulation distance between the winding and the outside world.

A single winding is impractical and current practice entails dipole-type windings with a separation distance $2 b$. In this case the gradient is of the order $B / b$. As $b$ is increased the force is reduced but the height of the field region is increased, so that a practical compromise must be reached [6].

There are two ways to use this force:

i. In a "falling curtain" separator the particles fall under gravity past the magnet (see Fig. 3), the mags being deflected inward $[2,3]$.

ii. In a drum separator the mags are held against a rotating drum, while the non-mags are thrown off under the influence of gravity and rotation [7, 8]. This is illustrated in fig. 4 .

Both designs have advantages and disadvantages, but in general, it may be said that falling curtain separators are better suited to fine particles ( 0.1 to $1 \mathrm{~mm})$, while drum separators are best for larger particles (up to $10 \mathrm{~mm}$ ). 
MAGNETIC

SUSCEPTIBILITY

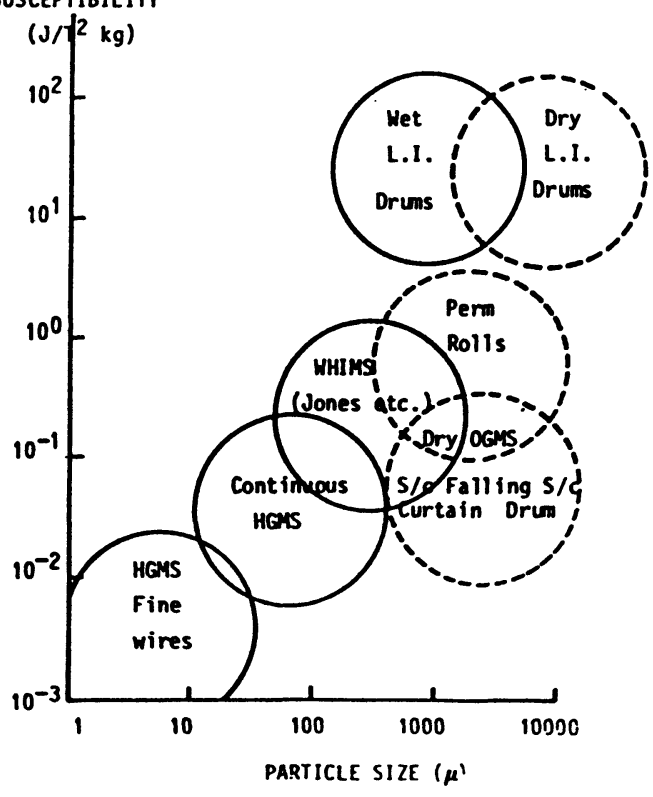

FIGURE 2. The applicability of magnetic separation as a function of susceptibility and particle size.

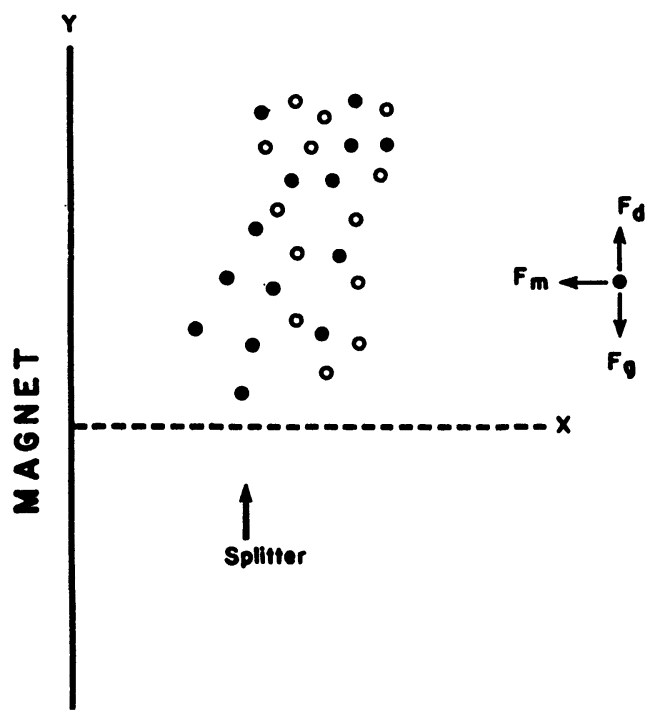

FIGURE 3. principle of falling curtain separators 
Capacity estimates for open-gradient separators

The deflection of mags in a falling curtain separator is

$$
\text { so }=\text { at }^{2} / 2=\left(X / \mu_{0}\right) \text { B. } \nabla \text { B. }(\mathrm{h} / \mathrm{v})^{2} / 2
$$

where a is the mean "magnetic acceleration" and the "residence time" of the particles of velocity $v$ in the field of height $\mathrm{h}$. Values between 20 and $200 \mathrm{~mm}$ are normally encountered [9].

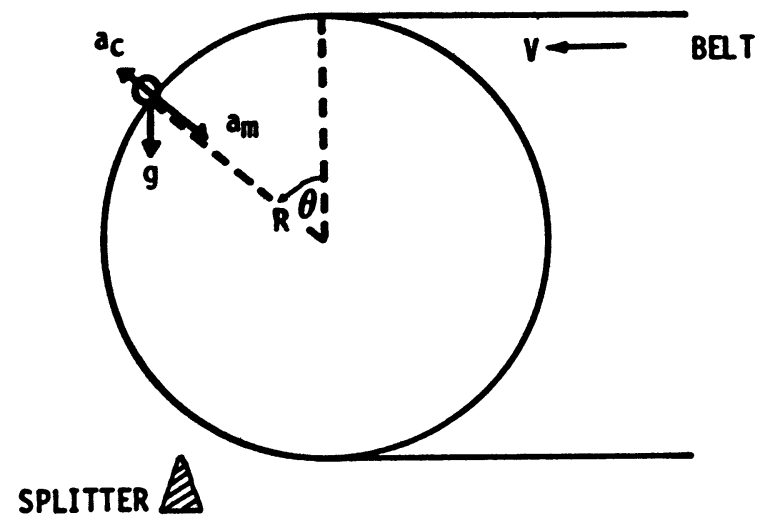

FIGURE 4. The principle of drum separators

In dense streams of small particles collisions play a dominant role and the deflection is reduced to $(2 \mathrm{~s} 0 \lambda)^{1 / 2}$, where $\lambda$ is the "collision mean free path". For particles of mean size of $0.1 \mathrm{~mm}$ the effect is to reduce the deflection by a factor of about 3 [9].

The capacity of such a separator is

$$
Q=3.6 \mathrm{LtDrv} \quad(\mathrm{t} / \mathrm{h})
$$

where $L$ is the curtain length, $t$ its width, $D$ the mineral density, $r$ the relative particle density and $v$ the stream velocity. $t$ is limited to $s$ or $s$ and typical values are 5 to $10 \mathrm{t} / \mathrm{h}$ per meter of magnet length. The presence of collisions leads to a deterioration of the magnetic product, so that further passes may be required [10].

In drum separators of drum length $L$ and drum speed $V$ the capacity for particles of average size $d$ is

$$
Q=2 \operatorname{LVDd} \quad(t / h)
$$

Typical values range from 10 to $30 \mathrm{t} / \mathrm{h}$ per meter for millimeter-sized particles [8]. 


\section{MAGNETS FOR MATRIX SEPARATION}

These are essentially solenoids of room temperature bore $D$ and length $L$ with a central field Bo. For thin-walled solenoids

$$
\mathrm{B}_{0}=\mu_{0} \mathrm{Ni} /\left(\mathrm{L}^{2}+\mathrm{D}^{2}\right)^{1 / 2}
$$

where $N$ is the number of turns and $i$ the current. As a practical design we consider a solenoid with $L=D=0.5 \mathrm{~m}$, and a current of $100 \mathrm{~A}$. The central field will be $4 \mathrm{~T}$ for 22 500 turns, or a total wire length of $36 \mathrm{~km}$. The inductance will be $170 \mathrm{H}$ and the stored magnetic energy $850 \mathrm{~kJ}$ (see [11] for details).

The chief limitation is the maximum single turn hoop stress $\mathrm{JBD} / 2$, where $J$ is the current density in the wire and $B$ the maximum field in the winding (a little greater than $\left.B_{0}\right)$. An acceptable limit for NbTi-Cu composite is about $250 \mathrm{MPa}$ [11].

\section{Capacity of matrix separators}

The capture and retention of magnetic particles is governed mainly by the matrix and the flow conditions [12]. An upper limit for the slurry velocity through the matrix is

$$
\mathrm{v}=\mathrm{d}^{2} \mathrm{D} X \mathrm{BB}=/ 18 \eta \mathrm{a}
$$

where $\eta$ is the slurry viscosity. Typical values range from 1 to $100 \mathrm{~cm} / \mathrm{s}$. The lower values are encountered in kaolin processing, where the particle size is below $5 \mu m[5,13]$.

The capacity of a matrix separator is

$$
Q=3.6 \mathrm{AwvF} \quad(\mathrm{t} / \mathrm{h})
$$

where $A$ is the cross-sectional area of the matrix canister, w is the solids density of the feed, $v$ the slurry velocity and $F$ the duty factor or the fraction of time the separator is receiving feed. If $t$, is the feed time and $t a$ the "dead time",

$$
F=t: /\left(t_{2}+t_{\alpha}\right)
$$

Figure 5 shows the behaviour of $Q$ with $w$ and $t$. A small dead time can be achieved in three ways:

i. by ramping the field up and down rapidly

ii. by using a "reciprocator" (see Fig. 6), where $t$ is limited to the time to interchange matrix canisters iii. by using a continuously moving matrix, e.g. carousel. 


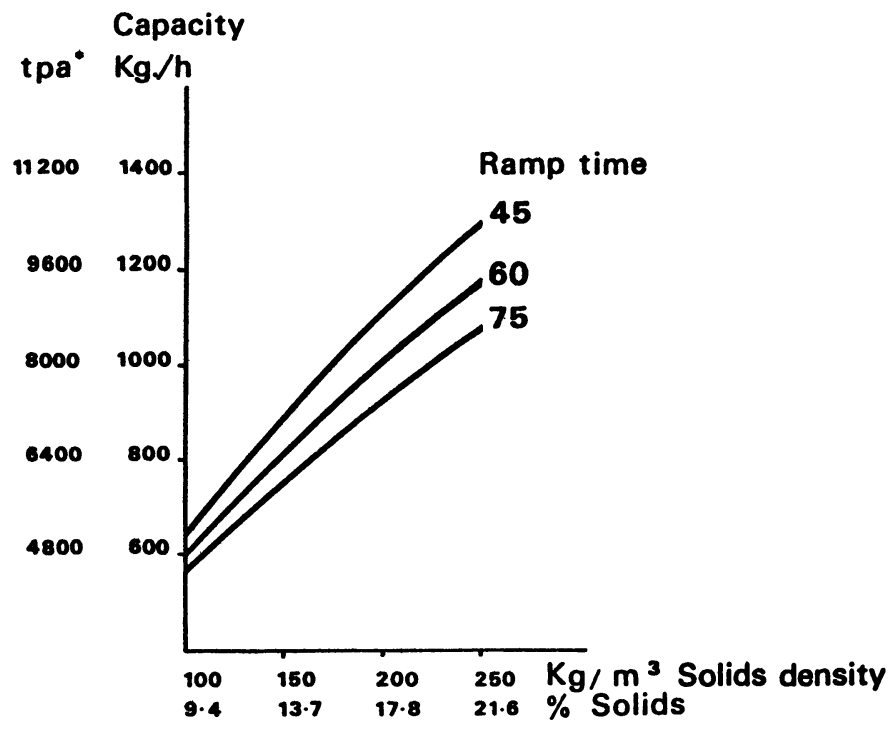

*Tons per annum

FIGURE 5. Capacity of a clay separator as a function of solids concentration and magnet ramp time in seconds. $(D=0.3 \mathrm{~m}, H=$ $0.5 \mathrm{~m}, \mathrm{~B}=3 \mathrm{~T}$ ).

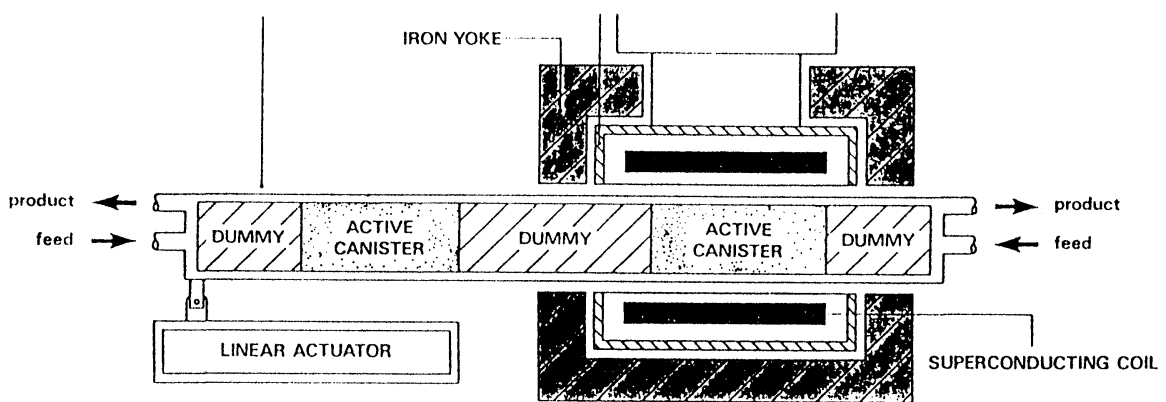

FIGURE 6. The principle of the reciprocating canister separator. 
The advantages of superconducting magnets

From (7) it appears that the magnetic velocity increases linearly with the applied field, so that doubling the field should allow one to double the slurry velocity and hence the capacity. The $B / v$ rule seems to apply to kaolin processing [14], but has not yet been fully accepted for other mineral separation problems [15].

The higher velocity can only be utilized fully if the duty factor is high. This implies a reciprocating or a continuously moving matrix, where the dead time is small [14]. It is possible to sweep a superconducting magnet fast (in about one minute or less) albeit at the cost of :

i. high helium boil-off due to hysteresis in the superconducting filaments and eddy currents in the connecting matrix (see below)

ii. large power supply to overcome the back emf of a high inductance. The power required to ramp a magnet of stored magnetic energy $E$ in a time $T$ is $2 E / T$. For $E=850 \mathrm{~kJ}$ and $\mathrm{T}=60 \mathrm{~s}$, this is $28 \mathrm{~kW}$.

\section{RUNNING COSTS OF SUPERCONDUCTING MAGNETS}

A large kaolin separation electromagnet may consume as much as $500 \mathrm{~kW}$ electric power, all of which is converted into heat. The main advantage of superconductivity is the lack of power dissipation in the magnet at fixed field. This must be paid for by the cooling of the magnet with liquid helium. For this reason it is of paramount importance to minimize the heat leaks into the cryostat.

These heat leaks arise from three main causes:

i. Radiation losses into the helium space, which are proportional to the fourth power of the shield temperature. Liquid nitrogen-cooled shields are generally used, but in addition there may be helium vapour-cooled shields at about $30 \mathrm{~K}$ or mechanical shield coolers. By careful design it is possible to reduce the heat inflow to less than $10 \mathrm{~mW} / \mathrm{m}[16]$.

ii. Conduction losses from the neck of the cryostat and the magnet supports can be minimized by careful design and the use of nylon supports. A $100 \mathrm{~kg}$ magnet capable of withstanding axial and radial forces of the order of 10 $k N$ has conduction losses of the order of $50 \mathrm{~mW}$.

iii. Current leads are a major contribution. Properly optimised vapour-cooled leads contribute about $2.1 \mathrm{~mW} / \mathrm{A}$. The zero-current value is about 40 per cent of this value and the overall boil-off depends on the duty factor of 
the magnet [11].

A superconducting switch allows the magnet to operate in "persistent mode". The current leads may then be detached so that the boil-off is greatly reduced. This dissipation in the switch can be made a small fraction of the stored magnetic

energy in the magnet [11].

If a magnet has to be ramped frequently from zero to a field

$B$ and back again, the main dissipation contributions are:

i. Hysteresis in the filaments, which can be reduced below $10 \mathrm{~kJ} / \mathrm{m}$ by reducing the filament size below $10 \mu \mathrm{m}$ [11].

ii. Eddy currents in the connecting matrix, which is reduced by twisting the filaments, increasing the matrix resistance by alloying and reducing the ramp rate. For ramp times of the order of one minute this contribution is normally small [11].

For the solenoids described above the boil-off is between 20 and $50 \mathrm{~cm}^{3}$ per cycle.

For a small system or a system that is used only occasionally simple bath cooling offers all advantages of reliability and low cost. The cost of delivered liquid helium varies from US $\$ 3$ to $\$ 15$ per liter, depending on quantity and locality, and liquid nitrogen costs are an order of magnitude lower. For larger systems a closed cycle refrigerator or separate liquefier is generally required [16]. Table II shows the reliability requirement pertaining in the mineral processing industry. Table III shows the cumulative cryogenic costs of various configurations for 5 years period.

TABLE II Acceptability criteria in the mining industry (based on [17]).

1. Average availability $>95$ per cent per annum

2. Mean time between failures $>8000$ hours

3. Ability to operate in adverse conditions of temperature, humidity and dust

4. Simplicity of operation to allow for lowquality labour

5. Fail-safe interlock system

6 . Short cool-down period $(<30$ hours after warmup, < 8 hours after quench)

It is clear that bath cooling is preferable for 25 per cent operation, while some helium conservation measure is 
required for 100 per cent operation. If each machine can process $5 \mathrm{t} / \mathrm{h}$, the minimum cryogenic cost per ton will be US\$2.00

TABLE II Cumulative cryogenic costs per magnet (US\$1000)

$\begin{array}{lcc} & \begin{array}{c}\text { Intensity of use } \\ 2000 \mathrm{~h} / \mathrm{a}\end{array} & 8000 \mathrm{~h} / \mathrm{a} \\ \text { 1. Bath cooling } & 60 & 240 \\ \text { 2. Coupled refrigerator } & 110 & 160 \\ \text { 3. Separate liquefier } & 50 & 80 \\ \text { (supplies 5 magnets) } & & \end{array}$

\section{LARGE EXISTING SUPERCONDUCTING SEPARATORS}

Table IV summarizes the relevant parameters of several recently built systems. Four have been successfully installed in the customers plants. Two are open-gradient separators while three are matrix machines. A detailed description follows below.

i. The KHD DESCOS drum separator magnet was desiened by KKA and built by Siemens [8]. The field was not high enough and the design of the windings ensured a low gradient, so that the machine is only really suitable for laree particles with fairly strong magnetic properties. This and the high price has denied it a market for a long time, but it was finally installed in a Turkish chromite mine to remove iron impurities.

ii. The CCL CRYOFOS is a linear dipole racetrack magnet designed for the dry separation of diamagnetic apatite from paramagnetic phlogopite in the size range 0.1 to $0.4 \mathrm{~mm}$. It suffered from repeated quenches, probably resulting from electro-mechanical stress [18]. The magnet was notable for its extremely small thermal insulation distance (10 mm between winding and room temperaturel.

iii. The Eriez 84" iron-clad solenoid is to a traditional design, but with very fast 60 s ramp time to $2 T$. This enables one to obtain a reasonable duty factor without resorting to mechanically complicated reciprocating matrix solutions [19]. The user seems very satisfied with the system and Fig. 7 shows a cost comparison with a conventional separator. 
TABLE IV Large superconducting separators

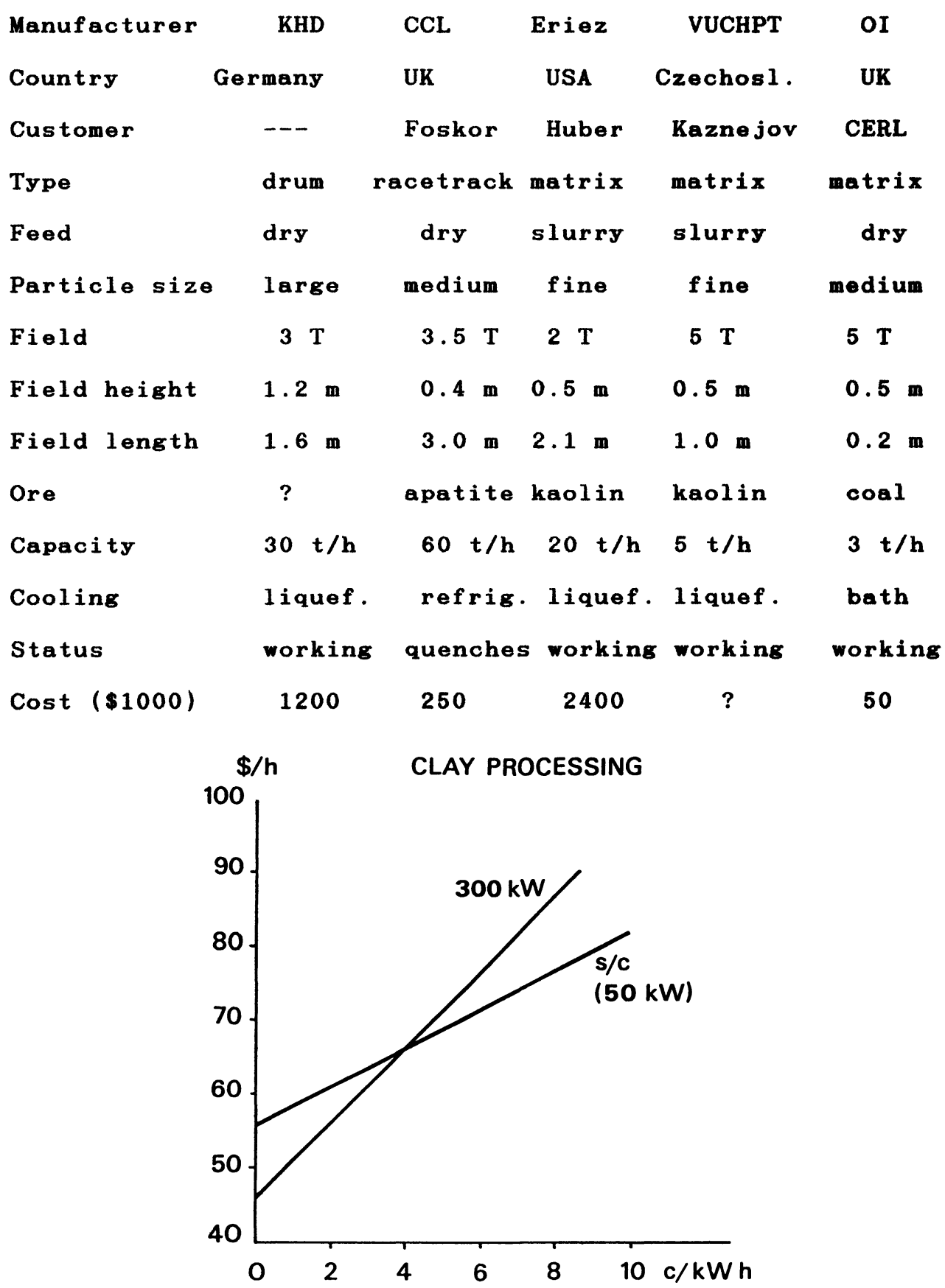

FIGURE 7. Cost comparison between conventional and superconducting separator in the US clay industry (from [22]). 
iv. The Czech reciprocating matrix kaolin separator has been in operation for over two years and seems to work well [20]. Its economic viability is questionable at this stage. Fig. 6 shows the reciprocator principle where active matrix canisters are moved between "dummy" canisters to reduce the out-of-balance forces.

v. The smaller Oxford Instruments magnet is used for pyrite and ash removal from pulverized coal [21]. The matrix canister is expelled in full field in less than 3 s using a secondary winding through which a current pulse is passed. This techniques is very suitable for matrix canisters of mass less than $25 \mathrm{~kg}$.

\section{HIGH-TEMPERATURE SUPERCONDUCTORS}

Recently much attention has focused on a new group of ceramic superconductors with critical temperatures above 90 $K[23,24]$. This suggests operation in liquid nitrogen, with great advantages in reduced cryogenic costs and greater simplicity. The acceptability in the very conservative mining industry will be greatly improved.

To estimate potential cost reductions using ceramic superconductors is extremely difficult at this stage. It is not known whether commercial production of wires or tapes is feasible and what current-carrying capacity of the new superconductors will be. Figure 8 shows a cost comparison with a standard NbTi conductor being used as a standard. It can be seen that the overall current density of the new materials must be in excess of $10 \mathrm{kA} / \mathrm{cm}^{2}$ before significant cost advantages accrue.

For medium-sized magnets capital costs tend to dominate cryogenic costs and hence large savings cannot be made. The situation is very different in power transmission lines, where the surface-to-volume ratio is large. It is very unlikely that liquid nitrogen-operated separation magnets will be available before 2000 .

\section{SUMMARY}

Superconducting magnets have fundamental advantages over conventional magnets when:

i. fields greater than $2 \mathrm{~T}$ are required

ii. large field volumes are required. 


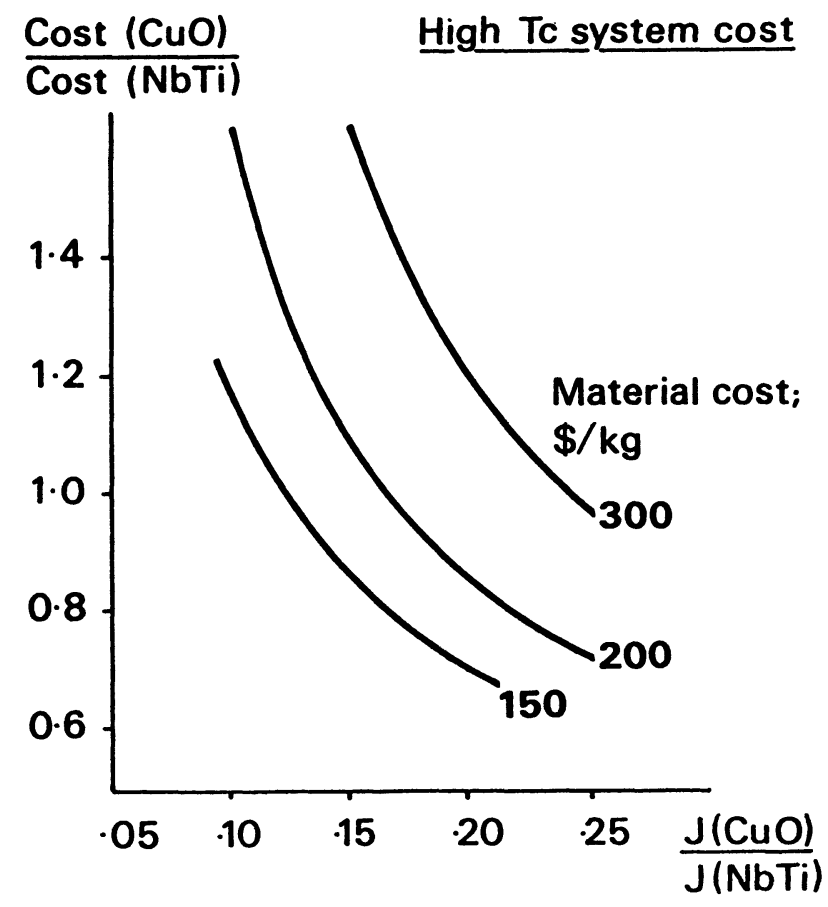

FIGURE 8. Cost comparison between conventional and high-temperature superconductors as a function of relative current density and unit material cost.

The relevant parameter is the stored magnetic energy

$$
E=V^{2} / 2 \mu_{0}
$$

where $V$ is the field volume and $B$ the average field. Figure 9 shows a schematic diagram of the capital cost versus stored magnetic energy.

It can be seen that for small systems permanent magnets are best, while for energies in excess of 1 MJ superconducting magnets are best. Considering the low running costs of permanent and superconducting magnets it appears that the range of applicability of conventional electromagnets is being severely squeezed. The major factor is the acceptability of cryomagnets in the industry, which improves as more systems are introduced and their reliability is demonstrated. Table 5 summarizes some of the current applications of magnetic separation. 
TABLE V Some applications of magnetic separation (based on [5]).

1. Beneficiation of weakly magnetic finely disseminated ores, e.g. iron, manganese, tin, tungsten

2. Retreatment of gold-bearing tailings dumps

3. Recovery of ilmenite and rutile from mineral sands

4. Beneficiation of industrial minerals, e.g. kaolin, fluorspar, apatite

5. Removal of pyrite and ash from pulverized coal

6. Waste water treatment in steel plants and power stations

7. Removal of radioactive solids in the nuclear industry

8. Magnetic filtration of gases

9. Magnetic separation of whole blood

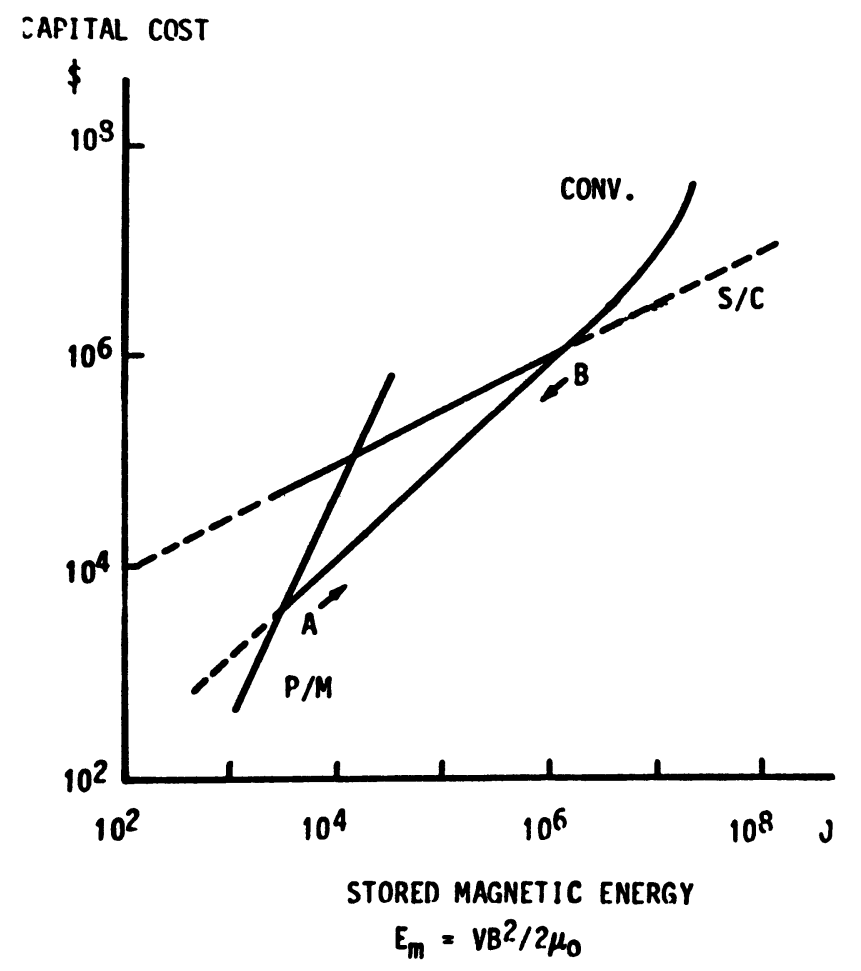

FIGURE 9 Capital cost versus stored magnetic energy for permanent, superconducting and conventional electromagnets 


\section{REFERENCES}

1. U. Andres, Magnetohydrodrnamic and Mennetohydrogtetic Methods of Mineral Separation (John Wiley, New York. 1976)

2. J. Kopp and J.A. Good, IEEE Trans. Mes. MAG-18, 833 (1982)

3. H.E. Cohen and J.A. Good, Proc. 11th Min. Proc. Conxress, Cagliari (Italy), (1375), Paper 28

4. P.G. Marston, J.J. Nolan and L.M. Lontai: Magnetic separation and magnetic separation methods. US Patent $3627678(1971)$

5. J. Sroboda, Magnetic Methods for the Treatment of Minorals (Elsevier, Amsterdam, 1987)

6. J. Kopp, Performance limits of open-gradient supercon ducting separators. Proc. INTERMAG Conf. Tokyo, Japan (1987)

7. J. Kopp, IEEE Trans. Mag. MAG-20, 1204 (1984)

8. K.H. Unkelbach and H.D. Wasmuth, A superconducting drumtype separator. Collog. Mag. Sep., Mintek, Randburg (South Africa), (1986)

9. J. Kopp, Int1. J. Min. Proc. 10, 297 (1983)

10. J. Kopp, Intl. J. Min. Proc. 18, 33 (1986)

11. M.N. Wilson, Superconducting Magnets (Clarendon Press, Oxford, 1983)

12. J.H.P. Watson, J. Appl. Phys. 44, 4209 (1973)

13. R.Gerber and R.R. Birss, High-Gradient Magnetic Separation (Research Studies Press, Chichester, 1983)

14. J.H.P. Watson, R.G. Scurlock and A.W. Swales, British Patent 8127084 (1981)

15. J. Svoboda, Mag. Sep. News 2, 51 (1986)

16. R.F. Barron, Cryogenic Systems (P, New York, 1985)

17. B.A. Wills, Mineral Processing Technology (Pergamon Press, Oxford, 1985)

18. J.A. Good, A.A. Stadtmuller and A.P. Murray, Proc. 9th Int1. Conf. Magnet Technology, Zurich (1985)

19. J.A. Selvaggi, P. van der Arend and J. Colwell, An in- 
dustrial superconducting high-gradient magnetic separator. Unpublished report (1987)

20. Z. Kaiser et al., Proc. 9th Int. Conf. Magnet Technology, Zurich (1985)

21. S.E. Male and D. Lal, Proc. 10th Int1. Conf. Magnet

Technology, Boston (1987)

22. J.H.P. Watson, personal communication

J. Kopp obtained a B.Sc. degree from the University of the Witwatersrand, Johannesburg, South Africa in 1963 and a PhD. degree from the Oxford University in 1969. After some years of wandering in North america he returned to South Africa to become Professor of physics in 1979.

His interest in magnetic separation dates from 1981, and between 1987 and 1989 he worked on this topic at Oxford Instruments in the U.K. He is currently writing a book and is engaged in various consulting roles.

Keywords: superconducting magnetic separation, high-gradient magnetic separation, open-gradient magnetic separation, capacity, running costs, high-temperature superconductors. 